\title{
A INDISCIPLINA NA EDUCAÇÃO INFANTIL: A IMPORTÂNCIA DE DISCERNIR E DISTINGUIR OS DETERMINANTES DA INDISCIPLINA EM SALA DE AULA
}

LIMA, Misleni Teixeira de ${ }^{1}$

\section{LIMA, Misleni Teixeira de. A Indisciplina na Educação Infantil: A Importância de} Discernir e Distinguir os Determinantes da Indisciplina em Sala de Aula. Revista Científica Multidisciplinar Núcleo do Conhecimento. Ano 03, Ed. 01, Vol. 04, pp. 147 159, Janeiro de 2018. ISSN:2448-0959

\section{RESUMO}

O presente artigo tem como objetivo uma reflexão de como a indisciplina configura-se nos ambientes escolares e como vem interferindo de forma negativa na prática pedagógica dos profissionais da educação, demonstrando também as causas e as possíveis intervenções a se fazer. As discussões aqui propostas giram em torno das perspectivas tradicionalista e construtivista de educação, embasadas nas obras de diversos autores. O trabalho encontra-se organizado em três partes. Na primeira delas aborda-se questionamentos sobre a indisciplina nos anos iniciais e se devemos fazer intervenções pedagógicas nessa fase ou não. Em seguida é feita uma análise sobre os principais determinantes da indisciplina escolar divididos entre fatores psicossociais e pedagógicos. No decorrer desse trabalho são apresentadas algumas considerações relevantes à prática docente.

Palavras-Chave: Indisciplina Escolar, Educação Infantil, Prática Docente.

${ }^{1}$ Graduanda do curso de Licenciatura em Pedagogia da Universidade Leonardo da Vinci (UNIASSELVI) em Itumbiara-GO. 


\section{INTRODUÇÃO}

O que vem a ser indisciplina? Seria possível falarmos de indisciplina nessa etapa da educação infantil? Assim, relevar uma ação que pode ser classificada como indisciplina e que na educação infantil se apresenta, claramente, diferenciada das demais, pode não só permitir a continuidade dessa manifestação, como também, afetar o desenvolvimento dessa criança, pois compromete o seu processo de aprendizagem, tendo como consequências possíveis, o comprometimento de seu desenvolvimento cognitivo, afetivo e moral.

De acordo com estudos da área da psicologia, adolescentes que geram problemas constantes na escola, geralmente, começam a apresentá-los em idade precoce. Alguns sinais podem aparecer em crianças a partir dos três anos de idade: hiperatividade, instabilidade emocional e agressividade.

Conforme pesquisas expostas ao longo do artigo a indisciplina nos espaços escolares encontra-se cada vez mais presente e a maioria dos professores deparam-se mediante a situações que não sabem como lidar com os casos de indisciplina em sala de aula, ocasionando assim um baixo rendimento escolar para a própria criança e consequentemente também para a turma.

\section{DESENVOLVIMENTO}

\section{A INDISCIPLINA NOS ANOS INICIAS}

A indisciplina no contexto escolar tem sido intensamente vivenciada por alunos e professores, causando prejuízo no rendimento escolar dos alunos. De acordo com o dicionário elaborado por ferreira (2008) define o termo como um procedimento, ato ou dito contrário à disciplina. Complementando a explicação o autor explica a palavra disciplina como: (1) regime de ordem imposta ou mesmo consentida, (2) ordem que convém ao bom funcionamento de uma organização, (3) relações de subordinação do aluno ao mestre, (4) submissão a um regulamento, etc. 
De acordo com rego (1996, p. 83), a indisciplina escolar é um dos temas atuais que mais preocupam os professores e todos os envolvidos neste ambiente, sejam pertencentes a escolas públicas ou particulares, a educação infantil, ao ensino fundamental ou médio e a distintos contextos sociais.

A etapa de ensino da educação infantil é o primeiro ambiente escolar a qual as crianças têm contato. É nesta fase também que elas começam a desenvolver as noções de valores, de justiça e de moralidade, e a aprimorarem seu desenvolvimento intelectual, social, motor e cognitivo.

Por esta ser uma etapa de escolarização em que as crianças ainda se encontram em formação de seus processos cognitivos, sociais e morais, alguns teóricos e profissionais da área da pedagogia e da educação infantil questionam se podemos pensar indisciplina nesse nível de ensino.

Seria possível falarmos de indisciplina nessa etapa da educação infantil? Segundo garcia (2008, p. 371) "um aluno indisciplinado seria não somente aquele cujas ações rompem com as regras da escola, mas também aquele que não está desenvolvendo suas próprias possibilidades cognitivas, atitudinais e morais", considerando que o aluno indisciplinado está, também, prejudicando seu próprio desenvolvimento.

Assim, relevar uma ação que pode ser classificada como indisciplina e que na educação infantil se apresenta, claramente, diferenciada das demais, pode não só permitir a continuidade dessa manifestação, como também, afetar o desenvolvimento dessa criança, pois compromete o seu processo de aprendizagem, tendo como consequências possíveis, o comprometimento de seu desenvolvimento cognitivo, afetivo e moral.

Em pesquisa realizada por kemple (1995, p. 108) em escolas públicas americanas, observou-se que a indisciplina é um dos problemas mais citados pelos professores de educação infantil e referenciada como um de seus maiores dilemas. A autora ainda argumenta que, na etapa de escolarização da educação infantil, devem-se enfatizar programas e atividades que promovam o desenvolvimento da criança em todas as 
áreas, incluindo o desenvolvimento do autocontrole, da responsabilidade e da autodisciplina. Outra pesquisa americana, conduzida por upshur, wenz-gross e reed (2009) em pré-escolas públicas e privadas, com crianças de 3 a 5 anos de idade, constatou que os problemas de indisciplina identificados na pré-escola que não tiveram intervenção, se agravaram nos anos escolares seguintes. Dentre esses problemas identificados na educação infantil, são descritas as atitudes de intolerância, de agressividade e de dificuldades de adaptação à realidade escolar. A pesquisa também aponta que as salas de aula que foram trabalhadas com um programa disciplinar de prevenção desses comportamentos, obtiveram uma redução das queixas de indisciplina pelos professores e melhores rendimentos dos alunos.

Muitos estudos pesquisados associam problemas de indisciplina na educação infantil aos problemas na alfabetização, ou seja, crianças indisciplinadas tendem a apresentar baixo rendimento e insucesso escolar, além de problemas no desenvolvimento social e moral.

As autoras stefan e miclea (2010, p. 1103) afirmam que a intervenção no início da escolarização da criança, ou seja, na educação infantil, "tem se tornado uma prática amplamente reconhecida, pois os anos pré-escolares oferecem o melhor momento para trabalhar com a prevenção de problemas, como a indisciplina escolar".

Podemos observar, assim, que para identificar, discernir e trabalhar com a prevenção da indisciplina na educação infantil, devemos considerar o envolvimento de vários fatores determinantes tanto no surgimento e na investigação das causas, quanto nas intervenções com intuitos preventivos das manifestações de indisciplina escolar. Como em qualquer outro contexto, o espaço da educação infantil também é marcado por diferentes manifestações de indisciplina e que podem ser melhor entendidas quando analisamos essa variedade de fatores que envolvem essas manifestações, como o contexto social e histórico em que a escola está inserida, as participações familiares, a concepção pedagógica da escola e dos professores, entre outros.

Vergés e sana (2009, p. 35) sugerem: 
O que devemos entender é que nenhum aluno nasce indisciplinado; ele se torna indisciplinado em determinadas situações, dependendo do sentido da indisciplina para ele naquele momento, com vários fatores que possam levá-lo a agir dessa forma.

Como as autoras sugerem acima, existem vários motivos pelo qual a criança age com atos de indisciplina, então não podemos tratá-la como fato isolado pois estão envolvidos vários fatores determinantes.

\section{DETERMINANTES DA INDISCIPLINA}

O aluno indisciplinado é aquele que não desenvolveu a autodisciplina, que não tem consciência dos efeitos do seu comportamento para o seu aprendizado, que não consegue discernir o certo do errado, que não respeita os princípios da democracia em um ambiente social e que, em consequência disso, acaba agindo de forma irresponsável, atrapalhando o andamento das aulas com atos de desrespeito, vandalismo e agressão.

É importante ressaltar que, de acordo com estudos da área da psicologia, adolescentes que geram problemas constantes na escola, geralmente, começam a apresentá-los em idade precoce. Alguns sinais podem aparecer em crianças a partir dos três anos de idade: hiperatividade, instabilidade emocional e agressividade. De acordo com oliveira (2005), a transformação histórico-social e as mudanças pedagógicas interferiram nas relações dentro da escola e, consequentemente, nas atitudes dos professores, que vão interferir, também, no comportamento das crianças, prejudicando a relação professor/aluno e aluno/aluno e, por vezes, acabam culminando em indisciplina.

\section{FATORES PSICOSSOCIAIS}

\section{A FAMÍLIA}

Há, ainda, casos em que os pais/responsáveis passam o dia fora de casa à procura de emprego ou trabalhando para garantir o sustento da família, não Ihes sobrando 
tempo para se dedicarem aos filhos. Em geral, em casos como esses as crianças passam o dia todo sozinha, em casa ou na rua. E os pais/responsáveis transferem para a escola a responsabilidade da educação de seus filhos: estabelecer limites e desenvolver hábitos.

Nessas famílias que se encontram desorientadas e desestruturadas muitas pessoas são alcoólatras, drogadas, violentas e, às vezes, agridem-se frente às crianças. Além de os responsáveis por cuidar e educar as crianças muitas vezes se agredirem, o pior é que a criança também é agredida por eles, então fica a cargo do professor ensinar às crianças desde amarrar os sapatos, dar iniciação religiosa até colocar limites que já deveriam vir esclarecidos de casa.

Há, também, situações opostas a essas: o excesso de mimos, a superproteção e a permissividade por parte dos pais/responsáveis também acarretam problemas de comportamento nessas crianças em casa e na escola. A criança educada dessa forma acha que todos estão a seu dispor para atendê-la e que não tem regras a seguir, tudo gira ao seu redor, ela é o centro das atenções. Em ambos os casos, os pais ou responsáveis não sabem como impor limites e esclarecer às crianças que elas têm direitos, mas também deveres a cumprir. Assim, no momento em que as crianças iniciam a vida escolar, levam consigo seus valores, hábitos, condutas, inseguranças, angústias, traumas e revoltas, que são reflexos de uma educação recebida no ambiente familiar.

\section{A MÍDIA}

A mídia por outro lado, quando os pais tentam estimular nas crianças uma educação respaldada em valores morais e éticos, a mídia, mais especificamente a televisão, tende a dificultar essa prática. As emissoras de tv, por meio de sua programação inescrupulosa, que tem como único objetivo aumentar seu ibope, incentiva a rebeldia, a competição, o individualismo, o sexo e a violência. 
Às vezes o professor presencia cenas de violência entre os alunos e não se dá conta de que eles podem estar simplesmente reproduzindo, dentro da escola, aquilo que viram na programação da tv, seja em filmes, seja em desenhos animados.

\section{A DIVERSIDADE ENTRE OS ALUNOS}

Quando falamos de diversidade nos referimos, por exemplo, às diferentes culturas com as quais nos defrontamos no âmbito escolar.

Esse é um fator com o qual os profissionais da educação devem se preocupar, pois, comumente, o professor não tem preparo para lidar com a diversidade e acaba determinando, às vezes inconscientemente, como aceitável o comportamento daquele aluno cujas atitudes e costumes demonstram proximidade com os seus valores, ou seja, com aquilo que ele julga ser o certo. Nesse caso, pode ocorrer que um aluno que não se enquadra no "modelo" estabelecido pelo professor passe a ser discriminado, fazendo com que o professor manifeste, mesmo que implicitamente, uma predileção por um ou outro aluno. Isso acaba prejudicando as crianças que são discriminadas, pois o professor passa a adotar tratamento diferenciado para os alunos.

Essa discriminação pode ocorrer não só em relação à cultura da criança, mas também no juízo que o professor faz do aluno, seja por sua aparência, pelo modo de se comportar, seja pela forma como se expressa, pela sua dificuldade em aprender os conteúdos, e tudo isso pode causar grandes conflitos em sala de aula.

Paulo freire (1997) ressalta que a resistência do professor em respeitar a 'leitura de mundo' com que o educando chega à escola, obviamente condicionada por sua cultura de classe e revelada em sua linguagem, constitui-se em um obstáculo ao conhecimento.

Outra situação gerada entre os alunos por causa da diferença pessoal/física a que o professor deve estar atento para coibi-la é o bullying. Bullying é uma palavra inglesa que significa "amedrontar, intimidar"; é uma ação da turma toda, ou quase toda, contra 
uma determinada criança, no sentido de provocá-la e intimidá-la por meio de ameaças. A criança vítima do bullying se vê acuada, sem poder reagir. É uma atitude de discriminação que a classe faz em relação a uma criança tida como "diferente" na sala de aula. Essa diferença pode ser em relação a porte físico (criança gorda ou magra demais, alta ou baixa, negra, albina) ou, ainda, em relação ao seu desempenho em sala de aula, como, por exemplo, a dificuldade na aprendizagem.

Outro fator relativo a diferenças individuais a que o professor precisa estar atento é que nem todos os alunos terminam a tarefa ao mesmo tempo, e proporcionar atividades extras para os alunos que terminam a tarefa antes dos colegas reduz a probabilidade de mau comportamento. Assim, é aconselhável organizar atividades pedagógicas diversificadas (jogos educativos) para os alunos mais rápidos, evitando o seu desassossego ao término da tarefa.

\section{PROBLEMAS DE DISTÚRBIOS DE ATENÇÃO}

Um caso de comportamento característico de distúrbio de atenção é, por exemplo, aquele em que a criança apresenta hiperatividade que prejudica a sua capacidade de concentração e atenção. Crianças e adolescentes que apresentam problemas visuais, auditivos, dificuldades de aprendizagem, entre outros, também podem revelar dificuldades na sua capacidade de concentração e atenção.

Se os educadores souberem diagnosticar esses distúrbios e ajudar no encaminhamento dessas crianças a um tratamento especializado estarão não só ajudando-as a superar ou lidar com o problema, como também evitarão que o comportamento delas culmine em indisciplina, influenciando negativamente o comportamento dos colegas. Entretanto, os professores têm que ter cautela para não encaminhar para tratamento crianças que tenham alguma dificuldade de aprendizagem, mas que, às vezes, precisam apenas de um pouco mais de atenção do professor e da família.

De acordo com josé e coelho (2006), os distúrbios de comportamento são classificados em duas categorias principais. O problema de conduta, que é RC: 13289

Disponível em: https://www.nucleodoconhecimento.com.br/educacao/indisciplina-na-educacaoinfantil 
caracterizado como aquele que perturba totalmente as outras pessoas, podendo ser dirigido contra elas, como a hostilidade, a agressividade, a destruição, a delinquência e a psicopatologia. O problema de personalidade é de caráter neurótico e pode ser chamado de "comportamento esquivo", ou seja, a criança tem medo dos outros, sentese ansiosa, evita situações que possam expô-la à crítica, ao ridículo ou à rejeição, podendo tornar-se hostil quando submetida a um alto grau de tensão. Esse problema é mais difícil de ser constatado, pois geralmente a criança apresenta-se submissa e obediente. Sabemos que detectar esses problemas não é uma tarefa fácil e que os professores enfrentam muitas dificuldades no seu cotidiano e, às vezes, não têm a quem recorrer na escola para compartilhar seus problemas. Mas, se os educadores ignorarem essas crianças, deixando-as de lado ou tratando-as como as demais, no que diz respeito à aprendizagem, poderão dificultar ainda mais sua prática pedagógica, pois enfrentarão outros tipos de problemas em sala de aula.

\section{CARÊNCIA AFETIVA}

Outro fator a ser considerado é que boa parte de nossas crianças apresenta uma carência afetiva muito grande, já que não puderam contar com os pais para lhes dar carinho, atenção, nem tampouco ouvi-las. Essa falta de carinho e de atenção que algumas crianças sofrem em casa pode, naturalmente, culminar em problemas de comportamento na escola. Isso ocorre porque a criança irá tentar a todo custo conquistar na escola o que não consegue em casa: a atenção das pessoas a sua volta. E ela fará o que for possível para atingir esse objetivo, ou seja, agirá das mais diversas formas para chamar a atenção dos colegas e professores.

Se o professor souber ouvir o aluno sobre suas dificuldades pessoais ou escolares já favorecerá, em muito, o relacionamento e o clima de sala de aula. Não se trata de atender as vontades dos alunos, mas de aproximar-se deles e conhecer suas dificuldades e sua realidade para melhor exercer seu papel de educar. O elogio, por exemplo, é uma forma de afetividade que ajuda a despertar no aluno a sua autoestima positiva e o gosto em aprender. 
Isso, provavelmente, fará com que o aluno se envolva cada vez mais nas atividades escolares, diminuindo a indisciplina na sala. Ao reconhecerem esse fato, os professores poderiam passar a valorizar e a destacar, de maneira sutil, por meio de elogios, mas sem comparações, os alunos atentos e participativos como forma de despertar na turma as vantagens de ser "bem-comportado".

\section{FATORES PEDAGÓGICOS}

\section{IMPOSIÇÃO OU FALTA DE REGRAS}

Para d'antola (1989), os bons professores estabelecem bem as regras e dão diretivas mais precisas; apresentam claramente suas expectativas quanto aos comportamentos dos alunos; respondem a estes de forma consistente; intervêm mais prontamente para parar o desvio e utilizam mais frequentemente as regras em caso de indisciplina. Mas, geralmente, as regras sequer são explicitadas ou discutidas com os alunos. O que comumente acontece na escola é que, quando se inicia um ano letivo, não há esclarecimentos, por parte dos educadores, sobre o que se espera dos alunos, como também não há orientação sobre as condutas que garantam o bom funcionamento do processo ensino/aprendizagem, como, por exemplo, o respeito entre os que estão envolvidos no cotidiano escolar.

Mas se a escola recebe os alunos com as regras já estabelecidas, sendo estas rígidas e incontestáveis, dificilmente a criança vai se adequar àquilo que a escola espera dela. Por isso, na elaboração das regras, devemos ouvir e respeitar a opinião dos alunos, pois esse deve ser um processo democrático e resultar do consenso entre os professores e os alunos quanto ao comportamento que se espera deles.

\section{FORMAÇÃO DOCENTE QUANTO ÀS QUESTÕES RELACIONAIS}

Se o professor tem dificuldade em lidar com toda essa complexidade do ambiente escolar e com a diversidade, certamente uma parcela da responsabilidade cabe aos cursos de formação de professores. Esses cursos, muitas vezes, não preparam o 
futuro educador para desenvolver seu trabalho pedagógico de acordo com a realidade dos educandos.

Uma formação voltada para uma atuação profissional mais consciente e ativa, na qual o professor deixe de ser um mero transmissor de conhecimento, poderia diminuir o problema da indisciplina dentro da sala de aula. Esse procedimento, na formação do educador, seria o que podemos chamar de medida de prevenção da disciplina, que, acreditamos, traria melhores resultados do que as medidas de correção ou punição frente às condutas já instaladas.

Não existindo uma formação pedagógica orientada por princípios de prevenção da indisciplina, o "mau" comportamento que algumas crianças apresentam no início da vida escolar pode se agravar, já que os professores não estarão preparados para lidar com determinadas atitudes dos alunos e estarão desprovidos de habilidades para o gerenciamento de sala de aula.

\section{A PROPOSTA PEDAGÓGICA DO PROFESSOR}

A ausência de uma proposta pedagógica bem elaborada pode ser outro determinante da indisciplina. Os conteúdos ministrados e a metodologia utilizada muitas linhas críticas, vezes não condizem com as expectativas e a realidade dos alunos, ou seja, os alunos não conseguem entender para que aprender determinadas matérias que não fazem sentido algum para sua vida cotidiana. E a forma como são transmitidas agrava ainda mais esse desinteresse, pois os conteúdos, com raras exceções, são passados de maneira fragmentada e desvinculados da realidade dos educandos.

Para que os alunos tenham interesse pela matéria, é preciso que o professor saiba qual a sua importância para a vida dos educandos e discuta com eles a razão de ser de cada conteúdo estudado. Trabalhar os conteúdos de forma crítica é importante tanto para despertar o interesse do aluno e evitar a indisciplina, como também para educar indivíduos conscientes. 


\section{O SISTEMA EDUCACIONAL E A ESCOLA}

O sistema educacional impõe um padrão tradicional de condutas rígidas que as instituições devem seguir e que, muitas vezes, estão fora da realidade particular de cada escola. Ainda que os professores tentem trabalhar sob essas normas, elas acabam causando tensão e desmotivando os profissionais para qualquer iniciativa.

A escola, nas últimas décadas, passou por transformações que interferiram diretamente em sua dinâmica, aumentando a incidência da indisciplina. Um dos indícios dessa transformação foi o aumento efetivo do número de vagas para o ensino fundamental e médio. A democratização da escola ocorreu sem que houvesse previamente uma estrutura básica que garantisse: a) acomodação adequada para os educandos (escolas e salas de aula com instalações apropriadas, carteiras escolares decentes e suficientes, espaço para recreação, entre outros aspectos); b) condições dignas de trabalho para o professor (materiais didáticos, mobiliário adequado e equipamentos necessários); c) preparação do professor para lidar com as diferentes realidades dos educandos; d) qualidade da educação oferecida.

Nesse contexto, a escola dificilmente poderá ser considerada um local agradável e, assim, para muitos alunos, frequentar a escola passa a ser uma obrigação, já que ela não tem atrativos e é uma imposição dos pais. Como a criança não vê saída para essa imposição, ela cria as mais diversas estratégias para amenizar a situação "desagradável" de sala de aula e frequenta a escola tendo em vista dois objetivos: divertir-se e ser aprovada. A aprendizagem e o conhecimento passam a ser ignorados.

\section{CONSIDERAÇÕES FINAIS}

Desenvolver um trabalho de qualidade e lidar com a indisciplina em sala de aula tornou-se um desafio inerente ao professor, de modo, que aumenta também a necessidade de pesquisar e implantar programas e práticas que amenizem e previnam os atos indisciplinados entre os alunos. 
Trabalhar de forma comprometida olhando individualmente para cada aluno, observando as reais necessidades de cada um e adotando uma metodologia eficaz permitirá que os alunos tenham um aprendizado completo, sendo esse um dever inerente ao professor que possui relações diretas com esses alunos, de modo, que este não deve simplesmente ser aquele mero professor transmissor do conhecimento.

Sabemos que essa responsabilidade não se remete somente ao professor, é necessário que a escola integralmente bem como a família também estejam envolvidas nesse processo de ensino- aprendizagem.

Para trabalhar diretamente sobre os fatores determinantes da indisciplina na educação infantil, é necessário distinguir e discernir as causas de tal comportamento, utilizando-se a metodologia adequada para cada caso. É claro que não resolverá o problema como um todo, mas, a criança em si como a turma terá um rendimento significativo no seu processo de ensino-aprendizagem melhorando o rendimento escolar e as relações aluno/professor e aluno/aluno.

\section{REFERÊNCIAS}

Barbosa, fernanda aparecida loiola. Indisciplina escolar: diferentes olhares teóricos. Ix congresso nacional de educação - educere, pucpr, 22 a 29 out. 2009.

Brasil. Ministério da educação e do desporto. Secretaria de educação fundamental. Referencial curricular nacional para a educação infantil. Brasília, 1998.

ferreira, a. B. H. Dicionário aurélio. 7. Ed. Curitiba: positivo, 2008.

Franzoloso, mariana ribeiro. Existe indisciplina na educação infantil? X congresso nacional de educação - educere, curitiba, 11 nov. 2011.

freire, paulo. Pedagogia da autonomia: saberes necessários à prática educativa. São paulo: paz e terra, 1997. 
Garcia, joe. Indisciplina na escola: questões sobre mudança de paradigma. Contrapontos, itajaí, n. 3, v. 8, p. 367-380, set/dez 2008.

José, elizabette da assunção; coelho, maria t. Problemas de aprendizagem. São paulo: ática, 2006.

Kemple, kristen. Discipline, management and education: rediscovering the whole child. In: teacher education quarterly. P. 107-115, mar 1995. 14. Ed. São paulo: summus, 1996. P. 83-101.

Oliveira, maria izete de. Indisciplina escolar: determinações, consequências e ações. Brasilia: liber livro, 2005

Oliveira, maria izete de. Fatores psico-sociais e pedagógicos da indisciplina: da infância à adolescência. Linhas críticas, brasília, n. 27, p. 289-305, jul./dez. 2009.

Rego, teresa cristina r. A indisciplina e o processo educativo: uma análise na perspectiva vygotskiana. In: aquino, júlio groppa (org). Indisciplina na escola: alternativas teóricas e práticas.

Stefan, catrinel; miclea, mircea. Prevention programmes targeting emotional and social development in preschoolers: current status and future directions. Early child development and care. N. 8, v. 180, p. 1103-1128, sep 2010.

Upshur, carole; wenz-gross, melodie; reed, george. A pilot study of eary childhood mental health consultation for children with behavioral problems in preschool. Early childhood research quarterly. N. 1, v. 24, p. 29-45, 2009. 